\title{
Willingness to Pay for Universal Health Coverage Scheme for Maternal and Child Health Care and Services in Benin
}

\author{
Adanmavokin Justin Sossou, ", Gilles Armand Sossou², Alphonse Kpozehoue ${ }^{3}$, \\ Babatounde Charlemagne Igue ${ }^{4}$, Edgard-Marius Ouendo ${ }^{5}$ \\ ${ }^{1}$ Adanmavokin Justin Sossou, Regional Institute of Public Health, University of Abomey Calavi, Ouidah, Benin Republic \\ ${ }^{2}$ Gilles Armand Sossou, Faculty of Economics and Management, University of Abomey Calavi, Abomey Calavi, Ouidah, Benin Republic \\ ${ }^{3}$ Alphonse Kpozehouè, Regional Institute of Public Health, University of Abomey Calavi, Benin Republic \\ ${ }^{4}$ Babatounde Charlemagne Igué, Faculty of Economics and Management, University of Abomey Calavi, Abomey Calavi, Benin Republic \\ ${ }^{5}$ Edgard-Marius Ouendo, Regional Institute of Public Health, University of Abomey Calavi, Ouidah, Benin Republic
}

Email address:

adanjus2014@gmail.com (A. J. Sossou)

*Corresponding author

\section{To cite this article:}

Adanmavokin Justin Sossou, Gilles Armand Sossou, Alphonse Kpozehoue, Babatounde Charlemagne Igue, Edgard-Marius Ouendo. Willingness to Pay for Universal Health Coverage Scheme for Maternal and Child Health Care and Services in Benin. Central African Journal of Public Health. Vol. 7, No. 3, 2021, pp. 111-120. doi: 10.11648/j.cajph.20210703.14

Received: April 27, 2021; Accepted: May 12, 2021; Published: May 27, 2021

\begin{abstract}
Enrolment in a universal health coverage scheme is a way to access health care and services and to reduce the catastrophic health expenditures that plunge already vulnerable populations into extreme poverty. As part of the analysis of the availability and operational capacity of health services in Benin (SARA 2018), an analysis of recipients' satisfaction and their willingness to pay for Universal Health Coverage scheme was carried out in 2018. This is a cross-sectional study with an analytical focus that covered 475 health facilities and 956 recipients of health care and services selected at random in health care structures and in the community. The dependent variable studied was the willingness to pay for Universal Health Coverage scheme and the explanatory variables were those relating to socio-cultural and economic factors and the reception of the recipient in the care environment. The hybrid bidding game technique was used to estimate the amount to be paid for the Universal Health Coverage scheme. Univariate and multivariate analyses were carried out to analyse the data. The data showed that Beninese people do not have a culture of early care-seeking; they get care when the episode of illness induces a temporary incapacity for work. The results observed showed that the following factors significantly influenced willingness to pay: being able to talk to the doctor, the feeling of being valued and treated with respect, the individual's ability to pay, access to pain management and temporary incapacity. In conjunction with the willingness to pay for Universal Health Coverage scheme, the payment amount, determined using the contingent valuation method, was 767 FCFA or US\$1.43 per month per individual. In view of these results and taking into account the socio-economic realities of the country where approximately $38.5 \%$ of the population is poor according to monetary poverty (Benin 2020), the pooling of health insurance coverage appears to be the solution to eliminate the financial barrier and the risks of catastrophic health expenditure. State subsidies for the contributions of populations in extreme poverty also appear necessary to ensure the sustainability, equity and sustainability of the health insurance scheme.
\end{abstract}

Keywords: Universal Health Coverage Scheme, Willingness to Pay, Enrolment, Payment Amount, Republic of Benin

\section{Introduction}

Universal Health Coverage (UHC) is designed to provide people with quality health care and services and reduce financial barriers, to prevent people from falling into extreme poverty as a result of catastrophic health expenses [1]. To achieve this, countries can choose between several schemes. These include the compulsory contributory scheme and the voluntary contributory 
scheme. However, compulsory UHC contribution only makes sense in a highly formalised environment. In sub-Saharan Africa in general and Benin in particular, the informal sector accounts for more than $90 \%$ [2]. According to the Global Burden of Disease, the Universal Health Coverage scheme index is 45 in Benin [3] and the coverage rate of health insurance schemes is about $1 \%$ of the population [4]. The incidence of population impoverishment due to catastrophic health expenditure is $1.6 \%$ in 2015 with an estimated population of over 11 million in 2016 [5]. The challenge for Benin is how to collect contributions from UHC recipients in a context where the informal sector accounts for $90 \%$ of the nation's businesses [4]. While the right to health is a fundamental right enshrined in Article 8 of the Constitution of December 11, 1990 and Act 019-40 of November 7, 2019 that amended it, since 2010 the Government of Benin has allocated less than $5 \%$ of the overall national budget to the health sector, far from the $15 \%$ benchmark set by the Abuja Declaration [6]. This state of affairs creates difficulties in achieving the Sustainable Development Goals (SDGs) 3.8.1 and 3.8.2. The need to use UHC scheme to provide the Beninese population with quality care and services by eliminating financial barriers is compelling. It is therefore essential to identify the factors that influence the implementation of UHC scheme.

A study carried out in Rwanda showed that UHC scheme was implemented through mutual health insurance groups adopting a policy of household coverage [7]. A systematic review of literature carried out in developing and transition countries shows that the major factors influencing enrolment in community-based health coverage are financial resources, high level of education, male gender, youth and large household size [8, 9]. Research in Bangladesh showed that patients' willingness to pay for UHC was influenced by a closer doctor-patient relationship, increased availability of medicines and increased chances of recovery [10].

The universal health coverage schemes implemented in Benin since 2008 have shown their limitations. The new impetus developed since 2016 through the "Assurance pour le Renforcement du Capital Humain" (ARCH) elected to create a separate "basket" for participants in extreme and non-extreme poverty, whom the state will systematically cover up to $100 \%$ and $40 \%$ respectively. This leaves individuals who can pay their contribution at liberty to choose their insurance [11]. This choice is a far cry from an insurance principle that recommends the mutualisation of risk. It is therefore essential to know what factors influence the willingness to enrol in and pay for universal maternal and child health care coverage in Benin.

The objective of this research is to determine what factors influence the willingness to pay for universal coverage of maternal and child health care and services in Benin.

\section{Methodology}

\subsection{Type of Study and Study Framework}

This study is part of the exploitation of the results of the Service Availability and Readiness Assessment (SARA+) survey that, as one of its outcomes, allowed for data collection on the satisfaction of patients attending health facilities. The health system in Benin is a three-tier pyramid structure made up of initial contact health facilities with a first reference level called the health zone, a second reference level called the Departmental Hospital, and a third reference level called the University Hospital Centre.

\subsection{Study Population}

The study population consisted of recipients of health care or health services. Specifically, mothers or "babysitters" of children and caregivers were included.

\subsection{Sampling of the Study}

A probabilistic method and a stratified random sampling technique based on the type of establishment (hospital, health centre, etc.), the managing authority (public, private), and department were used to select the health facilities included in the study. The list of health facilities included in the District Health Information Software 2 (DHIS2) in 2017 was used as a sampling frame.

The sample size was calculated in each stratum using the Schwartz formula

$$
\mathrm{n}=\mathrm{t}^{2} \times \mathrm{p} \times(1-\mathrm{p}) / \mathrm{sqm}
$$

$\mathrm{n}$ : Minimum sample size for obtaining significant results for an event and a set level of risk

t: Confidence level (the typical value of the $95 \%$ confidence level will be 1.96)

p: index of General Operational Capacity of health services by department based on the results of the SARA 2015 survey. General operational capacity of services refers to the capacity of health care institutions to provide basic health services. It takes into account the essential elements of layout and comfort, essential equipment, standard precautions for infection prevention, diagnostic capacity and essential medicines.

$\mathrm{m}$ : Margin of error set at $16 \%$ due to the complexity and disparity in the general operational capacity index for health services in each SARA 2015 department.

The sample size $n$ is obtained by summing the samples $n_{d}$ of each department and the total number of public and private hospitals (44). Each $n_{d}$ was calculated on the basis of the Schwartz formula with the above parameters and the general operational capacity index of health services at the level of each department.

Thus, the minimum size of the health facilities sampled is 452 , with a $5 \%$ increase that brings the total to 475 . In total, two recipients are expected per health facility, i.e., a total of 950 .

\subsection{Data Collection Method}

The survey was carried out at the same time as the SARA+ 2018 survey. The reference period for data collection was October 2018. A satisfaction questionnaire for clients or recipients of health care and services was administered to children's mothers or "babysitters", or to caregivers who 
received health care services. Among other things, recipients of health care and services were asked about their willingness to pay for the UHC for themselves and their family members. Recipients of health care and services who indicate willingness to pay for UHC are then asked what amount they are willing to pay. The input mask was designed on Cs-pro software and installed in the interviewers' tablets to allow data collection. A server enabled centralization of the databases. The hybrid auction game inspired by the work of Dieng [12] was used to determine the amount to be paid for $\mathrm{UHC}$ in Benin. The resulting minimum price is 500 FCFA, the average price is $1000 \mathrm{FCFA}$ and the maximum price is 5000 FCFA.

\section{Data Analysis}

Stata 14 software was used to process and analyse the collected data. We used the "Contingent Valuation" (CV) model [10] to estimate the willingness to pay for UHC in Benin. The Contingent Valuation method developed by Ciriacy-Wantrup (1947) is a direct interview technique that makes it possible to identify the preferences or the price that individuals (or households) are willing to pay for goods or services [13].

Proportions or percentages were calculated for qualitative variables. Means and their standard deviation or $95 \%$ confidence interval were determined for quantitative variables with a normal distribution.

To determine potential variables that could influence a householder's willingness to pay, we used 'probit' regression: i.e, the univariate regression between the dependent variable and the suspected relevant variable based on the literature review in order to select the list of explanatory variables to be included in the analysis model. Only variables with a $\mathrm{P}<0.20$ were included in the list of variables. From the relevant variables derived from the univariate regressions, a model was developed to determine the marginal effects and calculate the elasticity between the dependent variable (dv) and the explanatory variables. When willingness to pay is expressed, a second step of the analysis is to calculate the amount that each individual should pay for a fair and sustainable UHC in Benin. In this framework, the doublebounded under stata command inspired by the work of Lopez-Feldman (2012) was used [14]. The significance threshold for all statistical analyses was $5 \%$.

\section{Ethical considerations}

The survey objectives were explained to the participants and confidentiality and anonymity were guaranteed.

\section{Study Results}

\subsection{Socio-demographic Characteristics of Respondents}

Table 1 below summarises the socio-demographic characteristics of UHC respondents in Benin in 2018.

Table 1. Socio-demographic characteristics of UHC respondents in Benin in 2018.

\begin{tabular}{|c|c|c|c|}
\hline Variable & Category & Frequency & Percentage \\
\hline \multirow{2}{*}{ Gender } & Female & 528 & 55.23 \\
\hline & Male & 428 & 44.77 \\
\hline Existence of illness or accident & Yes & 753 & 78.93 \\
\hline \multirow{3}{*}{$\begin{array}{l}\text { Temporary Incapacity for Work (TIW) } \\
\text { due to illness }\end{array}$} & Yes & 558 & 74.10 \\
\hline & No & 195 & 25.90 \\
\hline & Less than a week & 371 & 66.49 \\
\hline \multirow{3}{*}{ Duration of TIW due to illness } & More than two weeks & 88 & 15.77 \\
\hline & Less than 1 kilometre & 257 & 26.88 \\
\hline & 1 to 2 kilometres & 231 & 24.16 \\
\hline \multirow[t]{3}{*}{ Household travel distance for UHC } & 2 to 5 kilometres & 252 & 26.36 \\
\hline & 5 to 15 kilometres & 127 & 13.28 \\
\hline & $15 \mathrm{~km}$. and over & 89 & 9.32 \\
\hline \multirow{2}{*}{ Willingness to enrol in a UHC scheme } & Yes & 583 & 61.11 \\
\hline & No & 371 & 38.89 \\
\hline \multirow{13}{*}{ Main health problem } & Diarrhoea & 31 & 4.12 \\
\hline & Accident/Injury & 55 & 7.30 \\
\hline & Dental problem & 5 & 0.66 \\
\hline & Skin problem & 7 & 0.93 \\
\hline & Eye disease & 4 & 0.53 \\
\hline & Blood pressure problem & 20 & 2.66 \\
\hline & Typhoid fever & 6 & 0.80 \\
\hline & Stomach problems & 15 & 1.99 \\
\hline & Sore throat & 1 & 0.13 \\
\hline & Cough, cold, flu & 51 & 6.77 \\
\hline & Diabetes & 7 & 0.93 \\
\hline & Others & 225 & 29.88 \\
\hline & NOT KNOWN & 4 & 0.53 \\
\hline
\end{tabular}

Source: Author, based on collected data 
In total, $55.23 \%$ of respondents were female and $78.93 \%$ had an illness. Of this population with an illness, $74.10 \%$ had experienced a temporary incapacity for work. Of this group total, $66.49 \%$ of sick respondents had one week of sick leave. As a whole, $26.88 \%$ of respondents resided less than $1 \mathrm{~km}$. from the health centre and $9.32 \%$ resided more than $15 \mathrm{~km}$. away. In total, $61.11 \%$ of respondents were willing to enrol in a UHC scheme and $89.39 \%$ of respondents noted that the medical team was prompt in responding to the demand for health care and services. Of this total, $73.44 \%$ of respondents felt valued and treated with respect and $73.12 \%$ were satisfied with their pain management. As for the condition that motivated the use of health care and services, malaria was in first place with $42.76 \%$ of respondents and $29.88 \%$ were suffering from other conditions. Other diseases include all diseases other than the first ten diseases notified in consultation.

\subsection{Economic Characteristics of Respondents}

Table 2 below summarises the economic characteristics of willingness-to-pay for UHC respondents in Benin.

Table 2. Economic characteristics of willingness-to-pay for UHC respondents in Benin in 2018.

\begin{tabular}{llll}
\hline Variable & Category & Frequency & Percentage \\
\hline & 0 & 251 & 26.31 \\
Average monthly income & $\leq 40000$ & 512 & 53.67 \\
& $>40000 \leq 100000$ & 139 & 14.57 \\
Cost of care & $>100000$ & 52 & 5.45 \\
& Not expensive & 673 & 89.38 \\
& Too expensive & 80 & 10.62 \\
CIVIL SERVANT & 55 & 5.77 \\
Respondent's Occupation & TRADES & 140 & 14.68 \\
& PUPIL/STUDENT & 117 & 12.26 \\
& HOUSEKEEPER & 197 & 20.65 \\
& FARMER & 197 & 20.65 \\
\end{tabular}

Source: Author, based on collected data

The results show that $26.31 \%$ of respondents had no average monthly income at all to declare. $53.67 \%$ of respondents had an average monthly income of less than or equal to 40000 FCFA francs and $89.38 \%$ of respondents noted that the cost of care was not expensive. $5.77 \%$ of respondents were civil servants, $20.65 \%$ were farmers and $20.65 \%$ were housekeepers. As a whole, $61.75 \%$ of respondents were ready to pay a contribution of 500 FCFA, $24.7 \%$ wanted to pay a contribution of 1000 FCFA and $13.55 \%$ were willing to pay 5000 FCFA.

\subsection{Characteristics of the Health Care and Services}

Table 3 below summarises the characteristics of the care as perceived by recipients.

Table 3. Summary of the characteristics of health care as perceived by recipients in Benin in 2018.

\begin{tabular}{|c|c|c|c|}
\hline Variables & Category & Frequency & Percentage \\
\hline \multirow{3}{*}{$\begin{array}{l}\text { Wait time for the care team } \\
\text { (promptness) }\end{array}$} & Yes & 673 & 89.38 \\
\hline & No & 80 & 10.62 \\
\hline & VERY SATISFIED & 194 & 25.76 \\
\hline \multirow{3}{*}{$\begin{array}{l}\text { Feeling of being listened to by health } \\
\text { care staff }\end{array}$} & SATISFIED & 509 & 67.6 \\
\hline & NOT VERY SATISFIED & 42 & 5.58 \\
\hline & NOT SATISFIED AT ALL & 8 & 1.06 \\
\hline \multirow{4}{*}{$\begin{array}{l}\text { Feeling of being valued and treated with } \\
\text { respect }\end{array}$} & VERY SATISFIED & 155 & 20.58 \\
\hline & SATISFIED & 553 & 73.44 \\
\hline & NOT VERY SATISFIED & 31 & 4,12 \\
\hline & NOT SATISFIED AT ALL & 14 & 1.86 \\
\hline \multirow{4}{*}{$\begin{array}{l}\text { Relief of physical and psychological } \\
\text { pain }\end{array}$} & VERY SATISFIED & 153 & 16 \\
\hline & SATISFIED & 699 & 73.12 \\
\hline & NOT VERY SATISFIED & 85 & 8.89 \\
\hline & NOT SATISFIED AT ALL & 19 & 1.99 \\
\hline \multirow{4}{*}{ How the recipient was examined } & VERY SATISFIED & 183 & 24.30 \\
\hline & SATISFIED & 525 & 69.72 \\
\hline & NOT VERY SATISFIED & 38 & 5.05 \\
\hline & NOT SATISFIED AT ALL & 7 & 0.93 \\
\hline
\end{tabular}

Source: Author, based on collected data

The results obtained from the recipients' perception of the current setup to provide care in response to the demand indicate that $89.38 \%$ of respondents noted short wait time for the care team (promptness). $67.6 \%$ of respondents were 
satisfied with the feeling of having been listened to by the care staff and $73.44 \%$ were satisfied that they felt valued and treated with respect. Furthermore, $73.12 \%$ of respondents were satisfied with the relief of their physical and psychological pain.

\subsection{List of Variables Relevant to Willingness to Pay for UHC Scheme}

Table 4 below summarises the list of variables relevant to willingness to pay for UHC in Benin in 2018.

Table 4. Summary of the list of variables relevant to willingness to pay for UHC in Benin in 2018.

\begin{tabular}{llll}
\hline Variable & Coef & $\boldsymbol{P}>|\mathbf{z}|$ & {$[\mathbf{9 5 \%}$ Conf. Interval] } \\
\hline Use of health services in the event of illness & -.2739307 & 0.013 & $-.4912374-.056624$ \\
Feeling of having been listened to by the doctor & -3779088 & 0.000 & $-.5420349-.2137827$ \\
Feeling of being valued and treated with respect & -.1998505 & 0.018 & $-.3651884-.0345126$ \\
Relief of physical and psychological pain & -2817364 & 0.001 & $-4425669-.120906$ \\
Temporary Incapacity for Work due to illness & .1856928 & 0.011 & 0.007 \\
Reception and use of given information & -.2541715 & 0.000 & -0420449.3293408 \\
Recipient sleeps under a mosquito net & -5680709 & 0.003 & $-4376492-0706938$ \\
How the patient was examined & -250202 & 0.003 & $-8281383-.3080035$ \\
Cost of health services & .4700868 & 0.026 \\
Ability to pay & -.2152563 & $-4172588-0831452$ \\
\hline
\end{tabular}

Source: Author, based on collected data

Overall, it is observed that: the variable "Temporary incapacity for work" is significant with a $\mathrm{P}$ value $(0.011)$, the variable "Recipient sleeping under a mosquito net" is relevant with a $\mathrm{P}$ value $(0.000)$, the variable "Cost of health services" is significant with a $P$ value $(0.003)$, the variable "Feeling of having been listened to by the doctor" is significant with a P value (0.000) and the variable "Relief of physical and psychological pain" is also significant with a $\mathrm{P}$ value $(0.001)$.

\subsection{Steps to Be Taken for Fair and Sustainable UHC (Universal Health Care) MCH (Maternal and Child Health) in Benin}

The steps to achieving equitable and sustainable UHC scheme $\mathrm{MCH}$ in Benin is assessed on the basis of the behaviour of the relevant variables integrated into the model.

Marginal effects

The multivariate analysis Table 5 below shows that more than half of the households surveyed were ready to pay voluntarily for UHC scheme; this probability was estimated at 0.61 .

Table 5. Multivariate analysis of willingness to pay for UHC in Benin.

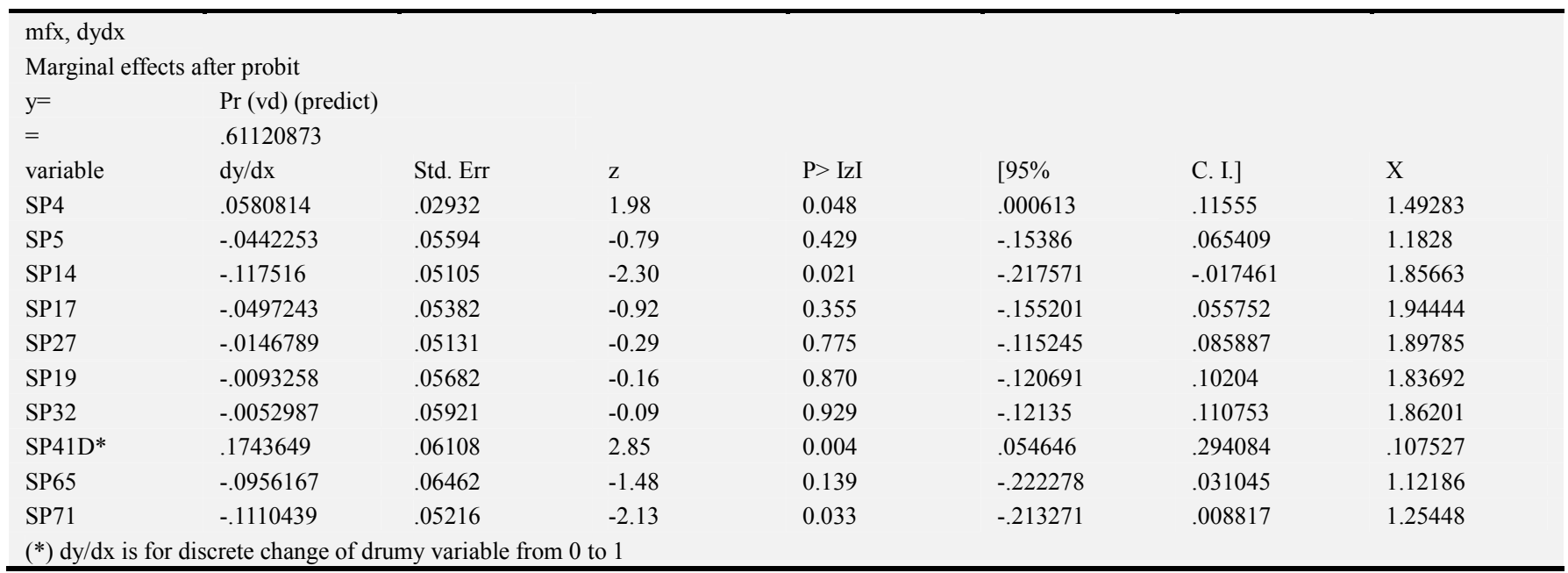

Source: Author, based on collected data

It is observed that the variables: "Use of health services in the event of illness" (SP5), "Management of physical and psychological pain relief" (SP17), "Feeling of being valued and treated with respect" (SP27), "How the patient was examined" (SP19), "Reception and use of information given" (SP32) and "Recipient sleeps under a mosquito net" (SP65) had no statistically significant impact on willingness to pay for UHC. The variables "Temporary incapacity to work due to illness" (SP4), "Cost of health services" (SP41D*) and "Ability to pay" (SP71) were statistically significant.

Determining the individual amount to be paid for a fair and sustainable UHC scheme in Benin 
Table 6. Below presents the results of the amount to be paid for UHC in Benin as well as the confidence intervals obtained.

\begin{tabular}{|c|c|c|c|c|c|c|}
\hline \multirow{2}{*}{\multicolumn{7}{|c|}{$\begin{array}{l}\text { Number of obs }=585 \\
\text { Wald chi } 2(0)= \\
\text { Prob }>\text { chi } 2=\end{array}$}} \\
\hline & & & & & & \\
\hline & Coef & Std. Err & $\mathrm{z}$ & $\mathrm{P}>\mathrm{IzI}$ & \multicolumn{2}{|l|}{$[95 \%$ Conf. Iterval] } \\
\hline Beta_cons & 766.6916 & 97.71311 & 7.85 & 0.000 & 575.1774 & 958.2058 \\
\hline Sigma_cons & 2035.095 & 103.5586 & 19.65 & 0.000 & 1832.124 & 2238.066 \\
\hline
\end{tabular}

Source: Author, based on collected data

The application of the double-bounded order from the Stata 14 software made it possible to note that the amount to be paid for a UHC in Benin was $767 \mathrm{~F}$ CFA with an IC95\% $=[575.17-958.20]$.

\section{Discussion}

This study was an opportunity to assess the factors that influence householders' willingness to pay in order to determine the way forward for a fair and sustainable UHC scheme $\mathrm{MCH}$ in Benin.

To our knowledge, this study is the first to attempt to determine the factors that would influence willingness to pay for UHC and estimate the amount to be paid in Benin.

The data used for this research comes from the Service Availability and Readiness Assessment (SARA+2018) survey data, which may be subject to transcription bias. However, these errors are minimized by the transcription in the SARA_chartbook_v2.2 matrix made available by the WHO. In addition, the works carried out by Bonato et al. [15] on the management of bias have served as a benchmark in the anticipation on the level of the questionnaires and in the processing of the responses. Within the framework of the analysis method, the data quality control carried out by the WHO Inter Country Team based in Ouagadougou (ISTOuagadougou) gives the authors assurance that potential biases are not of the kind that could compromise the quality and validity of the data used.

\subsection{Factors Influencing Willingness to Pay for Household MCH UHC Scheme Enrolment}

The question on the factors influencing willingness to pay for enrolment highlighted four important factors. These include the socio-cultural environment, the reception of the individual in the health care or health service environment, economic factors and individual factors.

\subsubsection{Socio-cultural Environment}

The question relating to the socio-cultural environment revealed that belonging to an ethnic group or religion has no influence on willingness to enrol in UHC in Benin. About 88\% of respondents rejected the influence of these factors. These results are supported by studies in Burkina Faso and Ethiopia that excluded religious affiliation as a factor influencing UHC scheme enrolment $[16,17]$.

However, in a study of Quality Adjusted Life Years (QALYs), religious affiliation was found to be a factor in maximizing utility [18]. Similarly, other studies conducted in
Lebanon, Nigeria and India have identified religion as a factor influencing equity, UHC scheme and hepatitis vaccination respectively [19-21].

While some studies have revealed the influence of ethnic and religious factors on UHC scheme enrolment, the reality in Benin is quite different and may well confirm these results. Secularism is clearly expressed in the country's constitution of December 11, 1990, and inter-religious and inter-ethnic marriage has become customary in the country. Certain religious or ethnic beliefs sometimes constitute obstacles to the use of health care and services, which is not the case in Benin. It is therefore not surprising that this factor does not influence UHC scheme enrolment in Benin.

In contrast, a study conducted in Cambodia in 2006 highlighted other socio-cultural factors that could effectively influence UHC scheme enrolment. These include "belief in the non-material causes of disease and remedies", a factor that in the Beninese context can be called the perception of the disease. This may well justify the behaviour of Beninese people who wait until the disease has worn off before turning to the health care system. As evidence, this study did indeed reveal that the people surveyed in the final phases of their illness experienced between one and three weeks of temporary incapacity to work. It will be interesting for a future study to investigate further the factors that cause health service users in Benin to wait until the disease wears off before seeking health care and services. It is clear that when you wait for an advanced level of disease deterioration before seeking care, the level of investment to regain better health and well-being is higher, resulting in catastrophic health expenditures that are costlier for the individual, the family and for the UHC scheme. Anticipating the factors that negatively influence UHC scheme is an excellent means of rationalization, minimizing the risk of adverse selection and promoting health and well-being, which is an objective of sustainable development. The results also showed that the variable temporary incapacity for work is relevant to the willingness to pay for UHC scheme. All other things being equal, this factor deserves full attention in the logic of developing behavioural change that is favourable to the sustainability and viability of the UHC scheme MCH strategy in Benin.

\subsubsection{The Reception of the Individual in the Health Care or Health Service Environment}

In measuring the influence of the individual's reception of UHC scheme enrolment, the study found that over $95 \%$ of recipients of health care and services were very satisfied and 
satisfied with the wait times for the care team (promptness), the doctor's willingness to listen, feeling valued and treated with respect, and physical management of pain. A proportion of $61.11 \%$ of these recipients were in favour of enrolling in a UHC scheme. An analysis of willingness to pay for UHC scheme in Bangladesh in 2015 revealed that the attitude of professionals at hospital level was $22.2 \%$ excellent and $67.1 \%$ good among health service recipients [10]. Studies conducted in Malaysia in 2012 and in some middle-income countries in 2015 on factors influencing willingness to pay revealed that the quality of health professionals' performance is a fundamental factor influencing willingness to pay for UHC scheme enrolment $[8,22]$. According to Bossyns P. et al., the UHC scheme makes no sense if the quality of care is not guaranteed or if the range of covered services is too limited. Moreover, in their studies, they consider that the UHC scheme appears to be a counter-weight for health care structures since the population is often unaware of the technical quality of the services offered to them due to moral hazard [23].

In view of all the above, it is important to note that the reception given to the recipients of health care and services determines the availability for use of health services and enrolment of the UHC scheme. It is therefore fair to say that the reception at the level of health care structures and services is supported by the quality of the services offered, which in turn is regulated by the mechanisms for structuring the demand for care. The quality of services influences the willingness of recipients to enrol in UHC scheme and the relationship between supply and demand is regulated by the social protection mechanism in place. It is in fact this social protection mechanism which, depending on the circumstances and policies in place, makes it possible to offer people access to quality health services. This is a Sustainable Development Goal (SDG 3.8.1) and the World Health Organisation (WHO) in its Thirteenth Global Work Plan calls on countries to begin the journey towards UHC scheme by offering people access to quality health services. In this study, the relief of physical and psychological pain, the feeling of having been listened to by the doctor, of being valued and treated with respect are all very relevant variables for UHC scheme enrolment that must be taken into account in the context of implementing a fair and sustainable UHC scheme in Benin.

\subsubsection{Economic Factors}

$71.66 \%$ of respondents indicated that economic factors influence UHC enrolment. These results are consistent with the work of Pavel S. et al., Adébayo E. F. et al., and Al-Hanawi, M. $\mathrm{K}$. et al., who found in 2015 and 2020 that socio-economic factors influence willingness to pay for improved access to quality care and UHC scheme enrolment [8, 10, 24]. These results are consistent with other studies that have shown that individuals with higher incomes and with children are prepared to pay to reduce health risk $[25,26]$. Brugiavin A. et al. also showed in the context of the scaling up of health insurance in Ghana that economic factors positively influence UHC scheme enrolment and improved maternal health [27]. Similarly, a study conducted in Ethiopia on civil servants showed that $42.6 \%$ of interviewees agreed that lack of income could be the main reason for not enrolling in UHC scheme and that those who agreed to enrol were ready to pay $3.6 \%$ of their monthly salary [28]. Work done in China in the informal sector on willingness to pay for UHC scheme showed that a $1 \%$ increase in the income of actors increases willingness to pay for UHC scheme and these actors were willing to pay $4.6 \%$ of their income [29]. Furthermore, a contingent evaluation carried out in Juba in 2017 to assess willingness to pay for UHC revealed that willingness to pay is mainly influenced by the existence of alternative sources of individual income and that recipients were willing to pay $5 \%$ of their total monthly income for UHC enrolment [30].

However, Acharya D. et al. in their studies in 2018 have shown that prior exposure to catastrophic health expenditures influences willingness to pay for UHC scheme [31]. Aizuddin A. N. et al. in their studies also find that UHC scheme enrolment is influenced by income but conclude that willingness to pay for health care involves more than just a person's financial capacity and has multifactoral influences [22].

Previous work and the results of this study have shown that the ability to pay and the cost of health services influence willingness to pay for UHC scheme. In the context of the balance and sustainability of UHC scheme in general and $\mathrm{MCH}$ in particular, the contribution of individuals and households alone cannot meet the true costs of health expenditure. In the impetus of achieving SDG 3, which aims to give individuals the means to live a healthy life and promote well-being at all ages by leaving no one behind, the State is called upon to fill the gap created by those whose income does not afford them the opportunity to enrol in UHC scheme. Moreover, even those who have the income cannot, on their own, contribute to health expenditure in the long term because it is recognised that health expenditure is catastrophic and can at any time plunge any individual into extreme poverty regardless of their status and income level.

Thus, while it is true that income is the main factor in UHC scheme enrolment, the State nevertheless plays a role through the subsidy and regulation of the UHC scheme in place. Preventing an individual or a household from falling into extreme poverty as a result of catastrophic health expenditure means offering them the opportunity to consume taxable goods and services on the market, which are a source of tax revenue for the state. In doing so, the State receives a return on investment through tax revenues.

The right to health is a fundamental right in Benin through article 8 of its constitution. In the impetus to provide its citizens with the best possible state of health, the Beninese state has developed 17 different subsidy mechanisms and targeted measures that are provided free of charge [32]. In 2018, the DHS 2018 reported: 391 maternal deaths per 100,000 live births, infant and child mortality is $96 \% 0$, infant mortality is $55 \% 0$ and neonatal mortality is $30 \% 0$ [4] while the country has a free caesarean section programme, a free programme for the care of pregnant women and children 
aged 0 to 5 years, a health fund for the destitute and others. A priori, this fragmentation of funding and the various mechanisms that accompany it are inoperative. In this context, UHC scheme appears to be a mechanism that will enable the optimization of resources with a higher comparative advantage for the state and equity in access to health care and services.

\subsubsection{Individual Factors}

The individual factors examined demonstrate the socioculture and the perception of disease in the Beninese population. The study revealed that more than $90 \%$ of respondents had at least one week of temporary incapacity for work and more during the last episode of illness. This result is a good illustration of what Beninese people expect when illness renders them incapacitated before seeking treatment. In such an environment, asking the beneficiaries of health services to mutualize health risk or to enrol in health insurance is unrealistic. This study confirms that it is unrealistic, as only $0.94 \%$ of respondents had health insurance. This is also confirmed by the results of the DHS 2018, which found, among other things, that $1 \%$ of women and men in Benin had health insurance [4]. There is ample evidence that delay in using the health care and service system leads to a fatal outcome for the patient. Better still, the physiological deterioration caused by the delay in starting treatment leads to the use of high-end drugs and an exponential increase in the cost of treating the disease. Ultimately, the delay in disease management leads to catastrophic health costs for the individual who has to pay more for care and also loses daily or monthly income due to temporary incapacity for work. The loss of income also affects the community around the patient who must stop working for hours at a time to attend the patient's bedside. The State also suffers losses as it has to deploy more resources for the care of the patient and it loses tax revenues because of the temporary incapacity for work and the nonconsumption of goods and services by the patient. Given the multi-tentacular implications of temporary incapacity for work due to illness, it is important to develop a behavioural change model to strengthen community commitment to early recourse to health care and services.

The study also found that $93 \%$ of respondents were satisfied with the feeling of being valued and treated with respect. These results could, of course, be due to the various reforms undertaken in the health system since 2016. In 2013, the private health sector captured $54 \%$ of the demand for care due to the quality of the reception reserved for recipients in public health care and service structures [33]. The diagnosis carried out by the commission in charge of health system reforms in 2016 also emphasised the quality of reception and poor management that influenced the performance of the health system [34]. With a view to the implementation of UHC scheme, it will therefore be necessary to capitalise on the current achievements in terms of reform and to strengthen dialogue between actors and stakeholders in order to significantly improve this performance.

\subsection{Steps to Be Taken to Achieve Fair and Sustainable UHC MCH in Benin}

The present study has highlighted factors that affect UHC scheme enrolment. These include: the possibility of talking to the doctor, the feeling of being valued and treated with respect, the ability to pay, pain management and temporary incapacity for work. These variables influencing the willingness to enrol in UHC scheme have also been highlighted in the work of Pavel S, et al. In a similar approach through the analysis of the marginal effects of the factors influencing the willingness to pay for UHC scheme, these authors found that the fact of meeting the same doctor ( $p$ value: 0.0003 ), the relationship between patient and doctor ( $p$ value: 0.0001 ), and the attitude of hospital staff ( $p$ value: 0.0003 ) are very significant [10]. In the present study, the possibility of talking to the doctor ( $p$ value: 0.036 ) can be equated with the close relationship between patient and doctor. Its significance further confirms the need to take this into account when defining the way forward for UHC scheme. The feeling of being valued and treated with respect ( $p$ value: 0.093 ) can be assimilated to the attitude of hospital staff ( $p$ value: 0.093 ). The significance of this variable also shows the steps to be taken within the framework of the strategic projections to make UHC scheme operational in Benin.

Analysis of the results of the marginal effects sufficiently shows that the relevant variables influencing willingness to pay must motivate the patient's decision as to whether or not to seek early access to health system, and also his or her determination to make timely, moderate health expenditures in order to avoid catastrophic health expenditures downstream. On closer inspection, these variables are manageable and all that is needed is the right communication with the population and the necessary support for community involvement to reverse the current trend.

Calculations based on the contingent valuation method indicate that the amount to be paid for fair and sustainable $\mathrm{UHC} \mathrm{MCH}$ in Benin is 767 FCFA or US\$1.43 ${ }^{1}$, with a confidence interval of $95 \%[575,1775,958,206]$. These results are in line with the margins within which people in low-income countries are willing to pay for UHC scheme and that were revealed by the work of Babatunde OA et al. that identified a payment amount between \$1.56 and \$7.5 [19].

In Benin the guaranteed minimum inter-professional wage is forty thousand $(40,000)$ CFA or US $\$ 86$. The average household size in Benin is 5.2 persons [4] and the monetary poverty rate is $38.5 \%$ [2]. Based on the amount to be paid and the size of the household, a head of household in Benin must pay US\$86 or $10.43 \%$ of the total annual household income for UHC scheme enrolment of all family members. An analysis at the $10 \%$ threshold indicates that a household with minimum wage income would fall into catastrophic health care spending by just paying for the enrolment of family members based on a willingness to pay set at US\$1.43.

1 Exchange rate $\$ 1=537.03 \mathrm{FCFA}$, rate on $01 / 04 / 2021$ at $1: 42$ Benin time. 
This analysis does not incorporate the co-payment that the household would be required to pay when health care and services are used. Thus, an episode of illness for this household plunges it into poverty, hence the need to resort to a mechanism for pooling the risk of illness. Paul et al. [35] in their study noted that the mechanism put in place through the "Assurance pour le Renforcement du Capital Humain" $(\mathrm{ARCH})$ would certainly reduce equity issues but the question of pooling the resources of the wealthy and well remains an equation to be resolved.

The question of risk pooling deserves to be explored further because it allows, on the basis of willingness to pay $\$ 1.43$, to recover about 46 billion 287 million 601 thousand 315 FCFA or US\$86 million 196 thousand 650 of contributions for $12,069,777$ inhabitants $^{2}$. As the monetary poverty rate in Benin is $38.5 \%$, the state, which in the dynamics of the ARCH roll out had planned to pay $100 \%$ of the contribution of the extreme poor, will therefore take charge of at least $38.5 \%$ of the total willingness to pay contribution to guarantee the solvency and sustainability of the scheme.

Contrary to the logic of $\mathrm{ARCH}$, which aims to have a separate basket dedicated to the population in extreme poverty, the State will have to create an impetus to stimulate the demand for care through a single organisation that will enable those who are able to pay to put their contributions into the common basket, and the State will have to provide its subsidy to enable the balance to be struck. In so doing, the State would significantly reduce the current high level of fragmentation of the health financing mechanism in Benin and provide the opportunity for the targets of different social nets to effectively access social protection schemes.

\section{Conclusion}

The study was an opportunity to show that the Beninese are not accustomed to early access to care; that the willingness to enrol in UHC scheme exists in Benin, and also that the willingness to pay for UHC scheme is US\$1.43. There are a number of triggers for willingness to pay for UHC scheme, including the opportunity to talk to the doctor, the feeling of being valued and treated with respect, individuals' ability to pay, pain management and temporary incapacity for work. An analysis of this willingness to pay makes it necessary to resort to State subsidy to pay the contribution of the extreme poor, estimated at $38.5 \%$ of the population, in order to ensure the sustainability of the scheme and its continued existence for the well-being of mothers and children.

\section{Conflict of Interest}

Authors do not declare any conflict of interest.

2 Ministry of Health of Benin, Health Statistics Yearbook, population of Benin in 2019 .

\section{Acknowledgements}

The authors would like to thank the Ministry of Health authorities at central, intermediate and peripheral levels for their participation in this study.

\section{References}

[1] WHO, The World Health Report Health Systems Financing The path to universal coverage 2010, http://apps.who.int/iris/bitstream/handle/10665/44372/978924 2564020 fre.pdf;jsessionid=7E793229C76F0A927607418266 143768? sequence $=1$, consult the $04 / 27 / 2021$ at 5 PM.

[2] Benin Républic and United nations Organization, Etude des impacts socio-économiques de la covid 19 au Bénin. 2020.

[3] Global Burden Deasis, Measuring universal health coverage based on an index of effective coverage of health services in 204 countries and territories, 1990-2019: a systematic analysis for the Global Burden of Disease Study 2019. Lancet, 2020. 1250 (84): p. 396.

[4] INSAE Bénin, ICF, Cinquième Enquête Démographique et de Santé (EDSB-V) 2017-2018, in Cotonou, Bénin et Rockville, Maryland, USA: INSAE et ICF. 2019, https://www.insaebj.org/images/docs/insae-statistiques/enquetesrecensements/EDS/2017-

2018/1.Benin EDSBV Rapport final.pdf, consult the 04/27/2021 at 6:15 PM.

[5] INSAE Bénin, P., ENQUETE MODULAIRE INTEGREE SUR LES CONDITIONS DE VIE DES MENAGES 3ème ÉDITION (EMICoV-2015).

2016 , file://C:/Users/SOSSOU\%20Justin\%20A/Downloads/Rapport pr\%C3\%A9liminaire_Emicov_2015(3).pdf, consult the le 04/27/2021 at 5:50 PM.

[6] Union Africaine, O., Abuja +12 Construire l'avenir de la santé en Afrique. 2013., https://www.unaids.org/sites/default/files/media_asset/JC2524 _Abuja_report_fr.pdf, consult at le 04/28/2021 at 7:05 PM.

[7] Lu C, C. B., Lewandowski JL, Basinga P, Hirschhorn LR, Hill K, Murray M, Binagwaho A, Towards Universal Health Coverage: An Evaluation of Rwanda Mutuelles in Its First Eight Years. PLoS ONE 2012.7 (6).

[8] Adebayo EF, U. O., Wiysonge CS, Erin A. Stern EA, Lamont KT and Ataguba JE, A systematic review of factors that affect uptake of community-based health insurance in low-income and middleincome countries. BMC Health Services Research 2015. 15 p. 543.

[9] Panda P, D. I., Koehlmoos TP, Hossain SAS, John D, Khan JAM and Dror DM, Factors affecting uptake of voluntary and community-based health insurance schemes in low-and middle-income countries: a systematic review, 27. London: International Initiative for Impact Evaluation (3ie). 3ie Systematic Review, 2016. 27 (London: International Initiative for Impact Evaluation (3ie)).

[10] Pavel, S., Chakrabarty, S., Gow, J., Assessing willingness to pay for health care quality improvements. BMC Health Serv Res, 2015. 15: p. 43.

[11] Bénin, A., Protéger les démunies et réduire la précarité 2017. 
[12] Dieng, A., Comparaison de trois techniques d'évaluation contingente: Le cas de la défaillance d'ovulation au Québec. 2018 ,

https://savoirs.usherbrooke.ca/bitstream/handle/11143/12213/

Dieng_Aissata_MSc_2018.pdf? sequence $=5$ \&isAllowed $=\mathrm{y}$, consult the le $\overline{04} / 17 / 2021$ at 5:13 PM.

[13] Parajuli Ashok., Application of Contingent Valuation Method in Natural Resource Management in Nepal. 2016. https://www.researchgate.net/publication/315201030, consult the $04 / 25 / 2021$

[14] Lopez-Feldman, A., Introduction to contingent valuation using Stata. 2012., https://mpra.ub.unimuenchen.de/41018/2/MPRA, consult the 03/05/2021.

[15] Bonato D, N. S., Tesler H., The Contingent Valuation Method in Health Care: An Economic Evaluation of Alzheimer's Disease. Institute of Economics, University of Bern 2001, https://www.researchgate.net/publication/8674311, consult the $08 / 24 / 2020$.

[16] DONG H, K. B., CAIRNS J, SAUERBORNR Differential willingness of household heads to pay community-based health insurance premia for themselves and other household members. HEALTH POLICY AND PLANNING, 2004. 19 (2): p. $120-126$.

[17] Molla, A. and N. Fentahun, Predictors of willingness to participate in health insurance services among the community of jimma town, southwest ethiopia. Health Serv Insights, 2014. 7: p. 31-7.

[18] Heale, W., Individualised and personalised QALYS in exceptional treatment decisions. J Med Ethics, 2016. 42 (10): p. 665-71.

[19] Babatunde OA, A. T., Salaudeen AG, Aderibigbe SA, Elegbede OE, Ayodele LM Willingness to Pay for Community Health Insurance and its Determinants among Household Heads in Rural Communities in North-Central Nigeria. ResearchGate, 2012. Vol. 2: p. pp. 133-142.

[20] Saleh, S. S., Alameddine, M. S., Natafgi, N. M., Acceptability of quality reporting and pay for performance among primary health centers in Lebanon. Int J Health Serv, 2013. 43 (4): p. 761-77.

[21] Khan, J., A. Shil, and S. K. Mohanty, Hepatitis B vaccination coverage across India: exploring the spatial heterogeneity and contextual determinants. BMC Public Health, 2019. 19 (1): p. 1263.

[22] Aizuddin NA, S. S., Aljunid MS, Factors influencing willingness to pay for healthcare. BMC Public Health 2, 2012, http://www.biomedcentral.com/1471-2458/12/S2/A37, consult the le $08 / 14 / 2020$.

[23] Paul Bossyns, F. L., Valéry Ridde Une assurance maladie à grande échelle pour le secteur informel en Afrique subsaharienne Six ans d'expérience au Sénégal rural 2012 2017 Studies in Health Services Organization \& Policy, 2018. 34.

[24] Al-Hanawi, M. K., O. Alsharqi, and K. Vaidya, Willingness to pay for improved public health care services in Saudi Arabia: a contingent valuation study among heads of Saudi households. Health Econ Policy Law, 2020. 15 (1): p. 72-93.

[25] Amiram Gafni, Willingness-to-pay as a measure of benefits. Relevant questions in the context of public decisionmaking about health care programs. Medical Care, 1991. 29 (12): p. 1246-5226.

[26] Cheng-Te Lin, Y.-S. H., Lu-Wen Liao \& Chung-Te Ting Measuring Consumer Willingness to Pay to Reduce Health Risks of Contracting Dengue Fever. Int. J. Environ. Res. Public Health, 2020. 17, 1810.

[27] Brugiavin A., P. N., Extending health insurance in Ghana: effects of the National Health Insurance Scheme on maternity care Health Economics Review 2016. 6 (7).

[28] Gidey T. M., G. G. B., Hogan M. E. \& Fenta T. G., Willingness to pay for social health insurance and its determinants among public servants in Mekelle City, Northern Ethiopia: a mixed methods study. Cost Ef Resour Alloc 2019. 17: 2 .

[29] Bärnighausen T., L. Y., Zhang X \& Sauerborn R., Willingness to pay for social health insurance among informal sector workers in Wuhan, China: a contingent valuation study. BMC Health Services Research, 2007. 7: 114.

[30] Basaza R., A. P. K., Kirabira P., Ogubi D. \& Lako R. L. L, Willingness to pay for National Health Insurance Fund among public servants in Juba City, South Sudan: a contingent evaluation. International Journal for Equity in Health 2017. 16: 158.

[31] Acharya D., D. B., Wagle BP Factors Associated to the Enrollment in Health Insurance: An Experience from Selected Districts of Nepal Canadian Center of Science and Education 2018. 152019 (2): p. 90.

[32] Ministry of Health Benin, National health financing strategy 2016-2022. 2015.

[33] Cuellar C., C. A., Harris A., Korynski P., Évaluation $d u$ secteur privé de la santé au Bénin. Bethesda, MD: Projet de Renforcement des résultats de santé au moyen du secteur privé, Abt Associates Inc. 2013: p. 106.

[34] Bénin, CTRSS, Report of the technical commission in charge of reforms in the health sector in Benin. 2017.

[35] Paul E., S. N., JWangbe JP, Fecher F, Bourgeois M, Budgeting challenges on the path towards universal health coverage: the case of Benin. Health Economics Review, 2020. 10 (28). 